\title{
Diagnostic and Prognostic Value of the Electrocardiogram in Stable Outpatients With Type 2 Diabetes
}

Mads Christian Tofte Gregers ( $\square$ mads.christian.tofte.gregers.01@regionh.dk )

Gentofte Hospital https://orcid.org/0000-0002-5887-2982

Morten Schou

Herlev Hospital

Magnus T. Jensen

Amager Hospital

Jesper Jensen

Herlev Hospital

Mark C. Petrie

University of Glasgow

Tina Vilsbøll

Rigshospitalet

Jens Peter Goetze

Rigshospitalet

Peter Rossing

Steno Diabetes Center Copenhagen

Peter G. Jørgensen

Gentofte Hospital

Original investigation

Keywords: Electrocardiogram, heart failure, diagnosis, prognosis, type-2-diabetes

Posted Date: September 9th, 2020

DOl: https://doi.org/10.21203/rs.3.rs-62837/v1

License: (c) (i) This work is licensed under a Creative Commons Attribution 4.0 International License.

Read Full License 


\section{Abstract}

Background: The 2019 European Society of Cardiology (ESC) guidelines on diabetes and cardiovascular disease (CVD) recommend an electrocardiogram (ECG) in patients with diabetes and hypertension or with suspected CVD, including heart failure (HF). The objective was to investigate whether ECG abnormalities can be used as a diagnostic and prognostic marker of HF in patients with type-2 diabetes (T2D) in secondary care diabetes-clinics.

Methods: A total of 722 patients with T2D in sinus rhythm were prospectively included. The ESC definition of HF with reduced and preserved ejection fraction (HFrEF and HFpEF) was used. An abnormal ECG was defined as having Q-waves, bundle-branch-block, left ventricular hypertrophy, or ST-T deviations. The composite endpoint was incident CVD and cardiovascular death.

Results: Overall, $24 \%$ patients had ECG abnormalities. A total of $13 \%$ had HF $(2.5 \% \mathrm{HFrEF}$ and $11 \%$ HFpEF) whereof 51\% had ECG abnormalities. A normal ECG had a $99.2 \%$ negative predictive value (NPV) of ruling out HFrEF. The ECG was less efficient in ruling out HFpEF (NPV of 92\%). In a multivariable analysis, the hazard-ratio (HR) of incident cardiovascular disease or death in patients with HFrEF or HFpEF and a normal ECG compared to patients without HF was 1.88 [1.00-3.53], $p=0.05$, while an abnormal ECG increased the HR to 3.62 [2.18-6.00], $p<0.001$.

Conclusion: HFrEF was rare and HFpEF was frequent in this T2D population. A normal ECG could safely rule out HFrEF but not HFpEF. The ECG carried prognostic information and an abnormal ECG increased the HR for incident cardiovascular event or cardiovascular death.

\section{Key Messages}

\section{What is already known about this subject?}

In early studies of unselected patients from primary care with suspected chronic heart failure, the presence of a normal ECG was found be useful to rule out heart failure with reduced ejection fraction.

\section{What does this study add?}

This study confirms that a standard electrocardiogram when normal in 722 stable outpatients with type 2 diabetes can be used to rule out heart failure with reduced ejection fraction. Further, it adds knowledge about the risk of incident cardiovascular disease or death as a pathologic electrocardiogram increases the hazard ratio.

\section{How might this implicate clinical practise?}

With this study clinicians in secondary diabetes care clinics can use an electrocardiogram to select patients to undergo echocardiography when suspecting heart failure with reduced ejection fraction, as a normal electrocardiogram will rule out this diagnosis with a negative predictive value of $>99 \%$. 


\section{Background}

Type 2 diabetes (T2D) is the ninth major cause of death worldwide (1) and the number of patients living with T2D is expected to increase dramatically in the coming decades (2). Heart failure (HF) in patients with T2D is receiving increasingly attention due to recent cardiovascular (CV) outcome trials and was found to be the second most common initial manifestation of cardiovascular disease (CVD) in T2D in a cohort of 1.9 million people (3). HF, however, can be difficult to recognise as the symptoms are nonspecific (4). This is illustrated by the fact that the presence of HF with reduced ejection fraction (HFrEF) and preserved ejection fraction (HFpEF) in patients with T2D is often unrecognised; though $4-28 \%$ of the patients suffer from HFrEF or HFpEF $(5,6)$. Early diagnosis and treatment of HF is of paramount importance; especially HFrEF for which there are many evidence-based therapies to improve the quantity and quality of life.

Echocardiography, the gold standard in diagnosing $\mathrm{HF}$ is, however, expensive and time-consuming and not widely available in the diabetes clinics. On the contrary, the electrocardiogram (ECG) is an inexpensive and easily available tool, that can assist in identifying individuals with T2D at high CV risk (7). Further, the European Society of Cardiology (ESC) recommends a resting ECG in patients with diabetes and diagnosed hypertension or with suspected CVD (8).

In early studies of unselected patients from primary care with suspected chronic HF, the presence of a normal ECG was found be useful to rule out HFrEF (9). However, the diagnostic accuracy of HF - HFrEF as well as HFpEF - in a contemporary T2D population is unknown. Also, the prognostic importance of HF in the absence of ECG abnormalities in patients with T2D is unknown. Thus, the aim of this study was to determine whether the ECG can be used as a diagnostic and prognostic marker for CVD events or CV death in T2D. Further, as T2D and incident CVD is closely related to the burden of prevailing other risk factors (10), we aimed to test whether including an evaluation of easy-accessible, routinely used and simple clinical risk factors (albuminuria, hypertension, body mass index $(\mathrm{BMI})<30$, and haemoglobin $\mathrm{A} 1 \mathrm{c}$ $<48 \mathrm{mmol} / \mathrm{mol}$ ) would increase the diagnostic precision of the ECG.

\section{Methods}

All participants were recruited from the Thousand\&2 Study with T2D patients followed at two secondary diabetes clinics in The Capital Region of Denmark: Steno Diabetes Center Copenhagen and the Diabetes Clinic at Herlev and Gentofte Hospital, University of Copenhagen. The study has previously been described in detail (11). In brief, a total of 2.158 T2D patients were invited to participate whereof 1.030 accepted. At study enrolment, patients were asked to fill out a standardised questionnaire with selfreported medical history including current medication, coronary heart disease (myocardial infarction, percutaneous coronary intervention, coronary artery bypass grafting), congestive HF, atrial fibrillation, self-reported dyspnoea, and cardiovascular risk factors (prior stroke, peripheral artery disease, family history of coronary artery disease, and smoking status). Laboratory values (cholesterol, high-density lipoprotein (HDL), low-density lipoprotein (LDL), triglyceride, haemoglobin A1c, and creatinine) were 
obtained from the electronic health records. NT-pro brain-natriuretic peptide (NT-proBNP) was measured by use of MAGLUMI ${ }^{\mathrm{TM}} 800$ Chemiluminescence Immunoassay by Snibe Diagnostics, Shenzhen, China. Albuminuria was defined as urine albumin/creatinine ratio above $30 \mathrm{mg}$ or urine albumin above 30 $\mathrm{mg} /$ day on at least 2 consecutive measurements. BMI was calculated from height- and weight measurements. Blood pressure was measured in supine position after 15 minutes rest with a validated device. Hypertension was defined as either a systolic blood pressure $>140 \mathrm{mmHg}$ or the ingestion of antihypertensive medication (e.g. beta blockers, calcium antagonists, angiotensin II receptor blocker, or angiotensin-converting enzyme inhibitor). These variables (haemoglobin A1c, systolic blood pressure, $\mathrm{BMI}$, albuminuria, and cholesterols) are all simple clinical risk factors for the development and progression of cardiac function in patients with T2D, measured as part of routine follow-up (12).

\section{Clinical examination}

A 12-lead ECG (Cardiosoft version 6.61, GE Healthcare) was recorded at the visit and interpreted by two independent investigators (MCG and PGJ), any disagreements were resolved with discussion. A normal ECG was defined as the absence of all the following: (1) left or right bundle branch block defined as QRScomplex duration >120 ms; (2) abnormal Q-waves defined as a Q-wave duration of $\geq 0.02 \mathrm{~s}$ in V2-3 and a duration and depth of $\geq 0.03 \mathrm{~s}$ and $\geq 1 \mathrm{~mm}$ respectively in any other leads; (3) left ventricular hypertrophy (LVH) according to the Sokolow-Lyon criteria; (4) ST deviations defined as ST-depression $\geq 0.5 \mathrm{~mm}$ or inverted T-waves $\geq 1 \mathrm{~mm}$. Echocardiographic recordings were performed and analysed by a single investigator (PGJ) in accordance with recommendations of the European Association of

Echocardiography and the American Association of Echocardiography. Further details with respect to the echocardiographic recordings are published elsewhere (13). Hence, both the ECG and echocardiography were performed on the same day. HFpEF was defined as: Patients with dyspnoea, with a NT-pro-BNP >125 $\mathrm{pg} / \mathrm{mL}$ and either one of the following four echocardiographic criteria fulfilled: (1) increased left ventricular mass index; (2) Septal E/e' >15; (3) left atrial size $>34 \mathrm{ml} / \mathrm{m}^{2}$; or (4) left ventricular ejection fraction between $41-50 \%$. HFrEF was defined as a left ventricular ejection fraction $\leq 40 \%$. In the present study, 308 patients were excluded (more than moderate heart valve disease or previous heart valve replacement $n=34$, missing NT-proBNP measurement $n=74$, missing ECGs $n=68$, missing echocardiographic measurement $n=69$, atrial fibrillation $n=62$, or missing follow-up data $n=1$ ). Patients with atrial fibrillation were excluded as they usually get a routine echocardiographic examination in Denmark. Further, E/e' is unusable in patients with ongoing atrial fibrillation and their NT-proBNP is usually elevated making the HF and especially the diagnosis of HFpEF difficult.

\section{Follow-up}

Follow-up was performed through national registers and the end-point was the composite of incident CV events (defined as coronary revascularization, myocardial infarction (ICD-10 codes I21-I25), heart failure (ICD-10 codes I11, I13, I42, I43 and I50), cardiac arrest (I46), cerebrovascular disease (160-169 and peripheral artery disease (170-179)) or CV death. 
Parametric and non-parametric analyses were used to compare groups were applicable. Sensitivity, specificity, positive predictive values (PPV), and negative predictive values (NPV) for the diagnostic value of ECG were all calculated in different subgroups of patients with HF (either HFrEF + HFpEF, HFrEF alone, or HFpEF alone). Receiver Operating Characteristic curves were applied to determine the ability of an ECG to diagnose HF when added to a multivariable logistic regression model adjusted for age, sex, albuminuria, haemoglobin A1c, BMI and systolic blood pressure. Cumulative incidence curves were used to examine the association with the composite endpoint with non-cardiovascular death as competing risk. Association with prognosis was examined using uni- and multivariable Cox proportionate hazard regression models including the beforementioned covariates. All statistics were calculated using $\mathrm{R}$ for Mac, version 2.15.3 (R Project for Statistical Computing, Vienna University of Economics and Business Administration, Wien, Austria).

\section{Approval}

The study was conducted in accordance with the Helsinki Declaration and approved by the Danish National Committee on Biomedical Research Ethics (amendment to protocol no. H-3-2009-139)(14). All participants gave written informed consent to participate in the study.

\section{Patient and public involvement}

No patients were involved in the design, recruitment, or interpretation of the results in this study.

\section{Results}

We included a total of 722 patients with T2D followed at secondary care clinics. Patient characteristics and baseline values are presented in table 1 . We identified 175 patients $(24 \%)$ with abnormal ECG findings (left $n=12$ or right $n=38$ bundle branch block, abnormal Q-waves $n=52$, LVH $n=7$, and STdeviations or inverted T-waves $n=66$ ). Overall, patients with abnormal ECG findings were significantly older, were more likely to have coronary heart disease and hypertension, had higher HDL-cholesterol and total cholesterol, a higher creatinine, a higher NT-proBNP, and were more often prescribed beta blockers and diuretics. Further, 18 patients $(2.5 \%)$ were diagnosed with HFrEF and 78 patients $(11 \%)$ were diagnosed with HFpEF.

Table 1: Population demographics. 


$\begin{array}{lll}\text { Normal ECG } & \text { Abnormal ECG } & \text { P-value } \\ \mathrm{n}=\mathbf{5 4 7} & \mathrm{n}=\mathbf{1 7 5} & \begin{array}{l}\text { (normal vs abnormal } \\ \text { ECG) }\end{array}\end{array}$

Clinical information

Age (years)

$64[56,69]$

$67[61,74]$

$<0.001$

Male sex (\%)

$349(63.8)$

$123(70.3)$

0.139

Diabetes duration (years)

$12[6,17]$

$12[5,19]$

0.879

Body mass index $(\mathrm{kg} / \mathrm{m} 2)$

29.1 [26.1, 33.0]

$29.3[26.7$, 33.2]

Systolic blood pressure $(\mathrm{mmHg})$

135 (16)

137 (18)

0.100

Diastolic blood pressure $(\mathrm{mmHg})$

$80(10)$

78 (11)

0.065

Coronary heart disease (\%)

63 (11.5)

70 (40.0)

$<0.001$

Hypertension, yes (\%)

$480(87.8)$

$165(94.3)$

0.022

\section{Laboratory values}

LDL-cholesterol ( $\mathrm{mmol} / \mathrm{l})$

$2.0[1.5,2.6] \quad 1.9[1.6,2.3] \quad 0.272$

HDL-cholesterol (mmol/l)

$1.2[0.9,1.5]$

$1.1[0.9,1.3]$

$<0.001$

Total Cholesterol $(\mathrm{mmol} / \mathrm{l})$

$4.1[3.5,4.8]$

$3.9[3.4,4.6]$

0.038

Albuminuria (\%)

$129(24)$

$44(25)$

0.826

Hemoglobin $\mathrm{A}_{1 \mathrm{c}}(\%)$

$55[48,65]$

$54[47,67]$

0.515

Hemoglobin $\mathrm{A}_{1 \mathrm{c}}(\mathrm{mmol} / \mathrm{mol})$

$7.5(1.43)$

$7.4(1.44)$

0.689

Creatinine $(\mu \mathrm{mol} / \mathrm{l})$

$77[65,94]$

$83[67,103]$

0.02

NT-proBNP (median [IQR]) 130.2 [73.2,
$305.2]$

270.1 [130.7, 623.1]

\section{Medications}

Metformin (\%)

$395(72)$

$120(69)$

0.406

DPP4 inhibitors (\%)

$56(10)$

$19(11)$

0.927

Sulfonylurea (\%)

88 (16)

$26(15)$

0.788

Glucagon-like peptide 1-receptor agonist (\%)

$134(25)$

42 (24)

0.974

Insulin (\%)

267 (49)

$82(47)$

0.716 


\begin{tabular}{|llll|}
\hline Beta blockers (\%) & $109(20)$ & $63(36)$ & $<0.001$ \\
\hline $\begin{array}{l}\text { Angiotensin-converting enzyme } \\
\text { inhibitors (\%) }\end{array}$ & $207(38)$ & $69(39)$ & 0.775 \\
\hline Angiotensin II receptor blockers (\%) & $210(38)$ & $72(41)$ & 0.575 \\
\hline Calcium antagonists (\%) & $172(31)$ & $60(34)$ & 0.543 \\
\hline Diuretics (\%) & $242(44)$ & $105(60)$ & $\mathbf{0 . 0 0 1}$ \\
\hline Statins (\%) & $428(78)$ & $144(82)$ & 0.298 \\
\hline
\end{tabular}

Association of ECG abnormalities and heart failure in all included patients

The sensitivity, specificity, NPV and PPV of ECG abnormalities for diagnosing HF in all patients and when stratified for either dyspnoea or presence of $0-1$ or $\geq 2$ simple clinical risk factors is presented in table 2 and 3.

Table 2: ECG as diagnostic tool for heart failure in all patients and in the subgroup of patients reporting dyspnea. 


\begin{tabular}{|c|c|c|c|c|c|c|}
\hline & \multicolumn{2}{|c|}{ Heart failure } & \multirow{2}{*}{$\begin{array}{l}\text { Sensitivity } \\
(\%)\end{array}$} & \multirow{2}{*}{$\begin{array}{l}\text { Specificity } \\
(\%)\end{array}$} & \multirow{2}{*}{$\begin{array}{l}\text { PPV } \\
(\%)\end{array}$} & \multirow{2}{*}{$\begin{array}{l}\text { NPV } \\
(\%)\end{array}$} \\
\hline & Yes & No & & & & \\
\hline All patients (either HFrEF or HFpEF) & $n=96$ & $n=626$ & & & & \\
\hline Normal ECG & 47 & 500 & \multirow[t]{2}{*}{51.0} & \multirow[t]{2}{*}{79.9} & \multirow[t]{2}{*}{28.0} & \multirow[t]{2}{*}{91.4} \\
\hline Abnormal ECG & 49 & 127 & & & & \\
\hline All patients (HFrEF) & $\mathrm{n}=18$ & $n=626$ & & & & \\
\hline Normal ECG & 4 & 500 & \multirow[t]{2}{*}{77.8} & \multirow[t]{2}{*}{79.9} & \multirow[t]{2}{*}{10.0} & \multirow[t]{2}{*}{99.2} \\
\hline Abnormal ECG & 14 & 126 & & & & \\
\hline All patients (HFpEF) & $\mathrm{n}=78$ & $n=626$ & & & & \\
\hline Normal ECG & 43 & 500 & \multirow[t]{2}{*}{44.9} & \multirow[t]{2}{*}{79.9} & \multirow[t]{2}{*}{21.7} & \multirow[t]{2}{*}{92.1} \\
\hline Abnormal ECG & 35 & 126 & & & & \\
\hline $\begin{array}{l}\text { Patients reporting dyspnea (either } \\
\text { HFrEF or HFpEF) }\end{array}$ & $\mathrm{n}=85$ & $n=180$ & & & & \\
\hline Normal ECG & 43 & 136 & \multirow[t]{2}{*}{49.9} & \multirow[t]{2}{*}{75.6} & \multirow[t]{2}{*}{48.8} & \multirow[t]{2}{*}{76.0} \\
\hline Abnormal ECG & 42 & 44 & & & & \\
\hline $\begin{array}{l}\text { Patients reporting dyspnea (HFrEF } \\
\text { alone) }\end{array}$ & $n=7$ & $n=180$ & & & & \\
\hline Normal ECG & 0 & 136 & \multirow[t]{2}{*}{100.0} & \multirow[t]{2}{*}{75.6} & \multirow[t]{2}{*}{13.7} & \multirow[t]{2}{*}{100.0} \\
\hline Abnormal ECG & 7 & 44 & & & & \\
\hline $\begin{array}{l}\text { Patients reporting dyspnea (HFpEF } \\
\text { alone) }\end{array}$ & $n=78$ & $n=180$ & & & & \\
\hline Normal ECG & 43 & 136 & \multirow[t]{2}{*}{44.9} & \multirow[t]{2}{*}{75.6} & \multirow[t]{2}{*}{44.3} & \multirow[t]{2}{*}{76.0} \\
\hline Abnormal ECG & 35 & 44 & & & & \\
\hline $\begin{array}{l}\text { Electrocardiogram (ECG). Hazard Ra } \\
\text { fraction (HFrEF and HFpEF). }\end{array}$ & R). $\mathrm{He}$ & failure & ith reduced & d preserved & jection & \\
\hline
\end{tabular}

Table 3: ECG as diagnostic tool for heart failure in the subgroups of patients with 0-1 and $\geq 2$ simple clinical risk factors. 


\begin{tabular}{|c|c|c|c|c|c|c|}
\hline & \multicolumn{2}{|c|}{ Heart failure } & \multirow{2}{*}{$\begin{array}{l}\text { Sensitivity } \\
\text { (\%) }\end{array}$} & \multirow{2}{*}{$\begin{array}{l}\text { Specificity } \\
\text { (\%) }\end{array}$} & \multirow{2}{*}{$\begin{array}{l}\text { PPV } \\
\text { (\%) }\end{array}$} & \multirow{2}{*}{$\begin{array}{l}\text { NPV } \\
(\%)\end{array}$} \\
\hline & Yes & No & & & & \\
\hline $\begin{array}{l}\text { Patients with 0-1 simple clinical risk } \\
\text { factors (either HFrEF or HFpEF) }\end{array}$ & $n=26$ & $n=279$ & & & & \\
\hline Normal ECG & 7 & 226 & \multirow[t]{2}{*}{73.1} & \multirow[t]{2}{*}{81.0} & \multirow[t]{2}{*}{26.4} & \multirow[t]{2}{*}{97.0} \\
\hline Abnormal ECG & 19 & 53 & & & & \\
\hline $\begin{array}{l}\text { Patients with 0-1 simple clinical risk } \\
\text { factors (HFrEF alone) }\end{array}$ & $n=7$ & $n=279$ & & & & \\
\hline Normal ECG & 1 & 226 & \multirow[t]{2}{*}{85.7} & \multirow[t]{2}{*}{81.0} & \multirow[t]{2}{*}{10.2} & \multirow[t]{2}{*}{99.6} \\
\hline Abnormal ECG & 6 & 53 & & & & \\
\hline $\begin{array}{l}\text { Patients with 0-1 simple clinical risk } \\
\text { factors (HFpEF alone) }\end{array}$ & $n=19$ & $n=226$ & & & & \\
\hline Normal ECG & 6 & 226 & \multirow[t]{2}{*}{68.4} & \multirow[t]{2}{*}{81.0} & \multirow[t]{2}{*}{19.7} & \multirow[t]{2}{*}{97.4} \\
\hline Abnormal ECG & 13 & 53 & & & & \\
\hline $\begin{array}{l}\text { Patients with } \geq 2 \text { simple clinical risk } \\
\text { factors (HFrEF+HFpEF) }\end{array}$ & $n=69$ & $n=311$ & & & & \\
\hline Normal ECG & 39 & 247 & \multirow[t]{2}{*}{43.5} & \multirow[t]{2}{*}{79.4} & \multirow[t]{2}{*}{31.9} & \multirow[t]{2}{*}{86.4} \\
\hline Abnormal ECG & 30 & 64 & & & & \\
\hline $\begin{array}{l}\text { Patients with } \geq 2 \text { simple clinical risk } \\
\text { factors (HFrEF alone) }\end{array}$ & $n=11$ & $n=311$ & & & & \\
\hline Normal ECG & 3 & 247 & \multirow[t]{2}{*}{72.7} & \multirow[t]{2}{*}{79.4} & \multirow[t]{2}{*}{11.1} & \multirow[t]{2}{*}{98.8} \\
\hline Abnormal ECG & 8 & 64 & & & & \\
\hline $\begin{array}{l}\text { Patients with } \geq 2 \text { simple clinical risk } \\
\text { factors (HFpEF alone) }\end{array}$ & $n=58$ & $n=311$ & & & & \\
\hline Normal ECG & 36 & 247 & \multirow[t]{2}{*}{37.9} & \multirow[t]{2}{*}{79.4} & \multirow[t]{2}{*}{25.6} & \multirow[t]{2}{*}{87.3} \\
\hline Abnormal ECG & 22 & 64 & & & & \\
\hline $\begin{array}{l}\text { Electrocardiogram (ECG). Haz } \\
\text { (HFrEF). Heart failure with pre }\end{array}$ & $\begin{aligned} \text { tio }(H \\
\text { ejecti }\end{aligned}$ & $\begin{array}{l}\text { Heart } f \\
\text { fractior }\end{array}$ & ure with re & ced ejection & action & \\
\hline
\end{tabular}

Of 722 included patients, 96 (13\%) had either HFrEF or HFpEF according to the applied definitions. Of these, 49 ( $51 \%$ of patients with HF) had an abnormal ECG. We found that the ability of the ECG to identify HF (HFrEF and HFpEF combined) was only moderate with an NPV of $91.4 \%$ and a low sensitivity. This was however, caused by an inefficient identification of patients with HFpEF (when excluding all patients 
with HFrEF) where the NPV was $92.1 \%$. For identification of HFrEF patients, the ECG could rule out this diagnosis when normal with an NPV of $99.2 \%$. Overall, the specificity of the ECG's ability to diagnose HF was around $80 \%$ with a low positive predictive value (PPV).

Adding ECG to a multivariate logistic regression model, in order to identify patients with HFrEF and HFpEF in the total population, increased the area under the curve from 0.73 to $0.77(p=0.019)$ (figure 1).

\section{Association of ECG abnormalities and HF in subgroups}

In a subgroup of patients reporting dyspnoea $(n=265)$ the ECG had poor diagnostic value with respect to identifying HF patients (HFrEF and HFpEF combined). However, when a normal ECG was recorded, HFrEF could be ruled out with high precision (NPV and sensitivity 100\%). All the data are summarised in table 2. In patients with 0-1 simple clinical risk factors (albuminuria, hypertension, $\mathrm{BMl}<30$, and haemoglobin A1c $<48 \mathrm{mmol} / \mathrm{mol})(\mathrm{n}=305)$ the diagnostic value of the ECG for HF (HFrEF + HFpEF) had an NPV of 97.0\%. In these patients, with few simple clinical risk factors, a normal ECG could rule out HFpEF with an NPV of $97.4 \%$ and a modest sensitivity. When dealing with both HFpEF and HFrEF combined and HFpEF alone in patients with $\geq 2$ clinical risk factors, the ECG did not prove useful to diagnose HF (see table 3 ). Overall, the specificity of the ECG's ability to diagnose HF was around $80 \%$ with a low PPV. Of note, for patients with 0-1 simple clinical risk factors, the ECG increased the area under the curve from 0.73 to 0.85 $(p=0.013)$ (figure 2).

Prognosis of patients with ECG abnormalities 


\begin{tabular}{|c|c|c|c|c|c|}
\hline \multirow[b]{2}{*}{$\begin{array}{l}\text { All patients with heart failure } \\
\text { (HFrEF+HFpEF) }\end{array}$} & \multirow{2}{*}{$\begin{array}{l}\mathrm{n} / \mathrm{no} \text { of } \\
\text { events }\end{array}$} & \multicolumn{2}{|l|}{ Univariable } & \multicolumn{2}{|c|}{ Multivariable* } \\
\hline & & $\mathrm{HR}(95 \% \mathrm{Cl})$ & $\begin{array}{l}\mathrm{P}- \\
\text { value }\end{array}$ & $\begin{array}{l}\mathrm{HR}(95 \% \\
\mathrm{Cl})\end{array}$ & $\begin{array}{l}\mathrm{P}- \\
\text { value }\end{array}$ \\
\hline No heart failure & $626 / 75$ & 1 & & 1 & \\
\hline HF with a normal ECG & $47 / 13$ & $\begin{array}{l}2.51(1.40- \\
4.53)\end{array}$ & 0.002 & $\begin{array}{l}1.88(1.00- \\
3.53)\end{array}$ & 0.050 \\
\hline HF with an abnormal ECG & $49 / 22$ & $\begin{array}{l}4.90(3.04- \\
7.88)\end{array}$ & $<0.001$ & $\begin{array}{l}3.62(2.18- \\
6.00)\end{array}$ & $<0.001$ \\
\hline \multicolumn{6}{|l|}{$\begin{array}{l}\text { Only patients with HFpEF (HFrEF } \\
\text { excluded) }\end{array}$} \\
\hline No heart failure & $626 / 75$ & 1 & & 1 & \\
\hline HFpEF with a normal ECG & $43 / 11$ & $\begin{array}{l}2.29(1.22- \\
4.32)\end{array}$ & 0.01 & $\begin{array}{l}1.63(0.83- \\
3.22)\end{array}$ & 0.16 \\
\hline HFpEF with an abnormal ECG & $35 / 15$ & $\begin{array}{l}4.60(2.64- \\
8.02)\end{array}$ & $<0.001$ & $\begin{array}{l}3.41(1.90- \\
6.11)\end{array}$ & $<0.001$ \\
\hline \multicolumn{6}{|c|}{$\begin{array}{l}\text { *Adjusted for age, sex, albuminuria, hemoglobin A1c, BMI and systolic blood pressure and known } \\
\text { cardiovascular disease. Electrocardiogram (ECG). Heart Failure (HF). Hazard Ratio (HR). Heart failure } \\
\text { with reduced ejection fraction (HFrEF). Heart failure with preserved ejection fraction (HFpEF). }\end{array}$} \\
\hline
\end{tabular}

During a median follow-up of 4.8 years [interquartile range: 4.1-5.3] a total of 110 (15.2\%) reached the composite end-point of incident CVD event or CV death. In a multivariable Cox Proportional Hazard Model, the hazard ratio (HR) of the composite end-point in patients with HF (HFrEF or HFpEF) and a normal ECG compared to patients without HF was associated with an increased HR of 1.88 [1.00-3.53] ( $p$ $=0.05)$. In patients with HF and an abnormal ECG the HR increased to $3.62[2.18-6.00](p<0.001)$ in the multivariable analysis compared to patients without HF. For HFpEF, the risk was attenuated when adjusting for clinical risk markers, however, HFpEF patients with an abnormal ECG still had a 3.5-fold increased risk of the composite end-point compared to patients without HF (table 4 and figure 3 ).

Table 4: Cox Proportional Hazard Model for HF admission or death in patients with HFrEF + HFpEF and HFpEF alone according to ECG findings.

\section{Discussion}

In this study we examined the accuracy of the ECG to diagnose HF in a contemporary cohort of patients with T2D. We found that, HFrEF was rare and HFpEF was common in this population and while ECG 
abnormalities were common and a normal ECG in general could be used to rule out HFrEF with a fair sensitivity and a high NPV, especially in patients reporting dyspnoea, this did not apply for HFpEF.

However, in a subgroup of patients with only 0-1 prevailing simple clinical risk factors, a normal ECG ruled out HFpEF with an NPV of $97.4 \%$ (though with a low sensitivity). Overall, the specificity of the ECG in diagnosing HF was around $80 \%$ with a low PPV. Adding ECG to clinical risk factors resulted in improved diagnostic accuracy assessed by improved area under the curve. Lastly, we affirmed that patients with HF had a worse prognosis compared to patients with T2D without HF - especially in the presence of an abnormal ECG.

\section{Our findings in relation to previous studies}

Our findings support a study of 534 non-diabetic patients referred by their general practitioner to echocardiography on suspicion of HF (9). In this study, a normal ECG (defined as the absence of atrial fibrillation, signs of previous myocardial infarction, LVH, bundle branch block, or left axis deviation) was found to rule out HFrEF, as none of the 96 patients (out of the total group of 534 patients) with impaired left ventricular function had a normal ECG. Another study found that the combination of a normal ECG and no previous history of myocardial infarction was an accurate predictor for normal left ventricular function in 320 non-diabetic patients referred with suspected HFrEF (15). Our study confirms and expands these findings regarding HFrEF to patients with T2D. A study from Boonman-de-Winther et. al. (16) concluded that a diagnostic screening model including medical history, physical examination, ECG, and NT-proBNP were useful to pre-select T2D patients for echocardiography which is in support of our findings.

We also examined the prognostic value of the ECG in both HFrEF and HFpEF. Not surprisingly, all patients with HF (both HFrEF and HFpEF) had a significantly increased risk of incident CVD event or CV death compared to patients with T2D without HF. In patients with HF, the ECG was able to identify HF patients with a very high risk of future events as patients with HF and an abnormal ECG had an approximately 3.5fold increased risk compared to patients without HF. The prognostic value of the ECG in patients with HF has previously been established, primarily in patients with HFrEF. Ramirez et al, identified an association of sudden cardiac death with certain types of ECG abnormalities in 650 HFrEF patients (17). The same group also found an improvement of a prediction model for sudden cardiac death when combining ECG with standard clinical variables in $597 \mathrm{HFrEF}$ patients (18). In the Candesartan in Heart failure: Assessment of Reduction in Mortality and Morbidity (CHARM) trial, which randomised 7.599 patients with symptomatic HF to receive candesartan or placebo, both bundle branch block and LVH were associated with a worse clinical outcome in patients with $\operatorname{HFrEF}(19,20)$. However, in HFpEF an ECG with bundle branch block had a more modest predictive effect while LVH in HFpEF patients was associated with CV death $(19,20)$. Another study with $3.425 \mathrm{HFpEF}$ patients found that an ECG with QRS-duration of $\geq 120$ ms identified subjects with a higher clinical risk of adverse outcomes (21). A prolonged QRSduration of $\geq 120$ ms has been shown to be predictive of long-term-mortality in hospitalised HFpEF patients (22). 
A major strength of this study is the careful characterisation of all included patients. A single investigator did all echocardiographic examinations thereby limiting interobserver variation. The study is limited in that all patients were recruited from secondary care diabetes units, making the results difficult to generalise to a primary care setting. Also, due to the observational nature of the study, there is an inherent risk of unmeasured confounding. Further, in our definition of an abnormal ECG, we included only the subset of abnormalities mostly associated with HF. Other abnormalities, such as prolonged PR interval or QTc prolongation were not included, which may represent a limitation in interpretation of the data. Lastly, only 18 of 722 patients had HFrEF in this population confirming that HFrEF is a rare complication in a general T2D outpatient setting. In general, the study findings need to be confirmed in larger cohorts of outpatients with T2D with an expected larger number of patients with HFrEF.

\section{Clinical perspectives}

Our data suggest that the ECG may be used routinely as a screening tool for HFrEF in patients with T2D in secondary care. HFrEF was a rare complication in this population. This high-lights a screening-based i.e. ECG - rather than a diagnostic - i.e. referring to echocardiography - strategy to identify type 2 diabetes patients with HFrEF. However, if there is suspicion of HFpEF, the patient should be referred for echocardiography, as the ECG cannot be used to rule out the condition - especially in patients with other prevailing risk factors.

\section{Conclusion}

In conclusion, HFrEF was uncommon and HFpEF was frequent among patients with T2D followed in a secondary care diabetes clinic. A normal ECG could safely rule out the presence of HFrEF but not HFpEF in this population - especially in patients with other prevailing risk factors for CVD. In follow-up analyses, the presence of an abnormal ECG in HF increased the risk of the composite endpoint of incident CVD event and CV death.

\section{Abbreviations}

Body mass index (BMI)

Cardiovascular disease (CV)

Electrocardiographic (ECG)

Heart failure (HF)

Heart failure with preserved ejection fraction (HFpEF)

Heart failure with reduced ejection fraction (HFrEF) 
Left ventricular hypertrophy (LVH)

Negative predictive value (NPV)

NT-pro natriuretic peptide (NT-proBNP)

Positive predictive value (PPV)

Type 2 diabetes (T2D)

\section{Declarations}

\section{Ethics approval and consent to participate}

The study was conducted in accordance with the Helsinki Declaration and approved by the Danish National Committee on Biomedical Research Ethics (amendment to protocol no. H-3-2009-139)(14). All participants gave written informed consent to participate in the study.

\section{Consent for publication}

Not applicable.

\section{Availability of data and materials}

The datasets generated during and/or analysed during the current study are available from the corresponding author on reasonable request.

\section{Funding}

This work was unfunded.

\section{Competing interest}

MCG, MS, JJ, MP, and JPG has no funding and no relations with the industry to declare.

MTJ has served as consultant, on advisory boards, or invited speaker for Astra Zeneca, Novo Nordisk, Novartis, and GE.

TV has received grants, consultancy and/or speaking fees from AstraZeneca, Boehringer Ingelheim, Gilead, Eli Lilly, MSD, Mundipharma, Novo Nordisk, Sanofi Aventis and SunPharma.

PR Consultancy and/or speaking fees (to his institution) from Astellas, AstraZeneca, Bayer, Boehringer Ingelheim, Gilead, Eli Lilly, MSD, Novo Nordisk and Sanofi Aventis and research grants to institution from AstraZeneca and Novo Nordisk.

PGJ reports receiving lecture fees from Novo Nordisk and Astra Zeneca. 
None of the authors have any conflict of interest to declare in relation to this work.

\section{Authors' contributions}

The authors MCG, MS, and PGJ contributed substantially to the planning, conception and design, acquisition of data, analysis and interpretation of data, and reporting of the work described in the article. The authors JJ, MP, JPG, TV, and RR contributed to the analysis and interpretation of data, and reporting of the work. All authors contributed to the manuscript and critically revised it before submission. The final submitted version to be published were approved by all authors.

\section{Acknowledgements}

Not applicable.

\section{References}

1. Zheng Y, Ley SH, Hu FB. Global aetiology and epidemiology of type 2 diabetes mellitus and its complications. Nat Rev Endocrinol. 2018;14(2):88-98.

2. Guariguata L, Whiting DR, Hambleton I, Beagley J, Linnenkamp U, Shaw JE. Global estimates of diabetes prevalence for 2013 and projections for 2035. Diabetes Res Clin Pract. 2014 Feb;103(2):137-49.

3. Shah AD, Langenberg C, Rapsomaniki E, Denaxas S, Pujades-Rodriguez M, Gale CP, Deanfield J, Smeeth L, Timmis A, Hemingway H. Type 2 diabetes and incidence of cardiovascular diseases: a cohort study in 1.9 million people. Lancet Diabetes Endocrinol. 2015 Feb;3(2):105-13.

4. Alexy T, Lebeis T, Cole R. Heart failure with reduced ejection fraction (HFREF) [Internet]. 1st ed. Nova Science Publishers, Inc.; 2018 [cited 2019 Oct 20]. Available from: https://experts.umn.edu/en/publications/heart-failure-with-reduced-ejection-fraction-hfref

5. Seferović PM, Petrie MC, Filippatos GS, Anker SD, Rosano G, Bauersachs J, Paulus WJ, Komajda M, Cosentino F, de Boer RA, et al. Type 2 diabetes mellitus and heart failure: a position statement from the Heart Failure Association of the European Society of Cardiology. Eur J Heart Fail. 2018;20(5):853-72.

6. Boonman-de Winter LJM, Rutten FH, Cramer MJM, Landman MJ, Liem AH, Rutten GEHM, Hoes AW. High prevalence of previously unknown heart failure and left ventricular dysfunction in patients with type 2 diabetes. Diabetologia. 2012 Aug;55(8):2154-62.

7. Okin PM, Devereux RB, Lee ET, Galloway JM, Howard BV, Strong Heart Study. Electrocardiographic repolarization complexity and abnormality predict all-cause and cardiovascular mortality in diabetes: the strong heart study. Diabetes. 2004 Feb;53(2):434-40.

8. Cosentino F, Grant PJ, Aboyans V, Bailey CJ, Ceriello A, Delgado V, Federici M, Filippatos G, Grobbee DE, Hansen TB, et al. 2019 ESC Guidelines on diabetes, pre-diabetes, and cardiovascular diseases developed in collaboration with the EASD. Eur Heart J. 2020 Jan 7;41(2):255-323. 
9. Davie AP, Francis CM, Love MP, Caruana L, Starkey IR, Shaw TR, Sutherland GR, McMurray JJ. Value of the electrocardiogram in identifying heart failure due to left ventricular systolic dysfunction. BMJ. 1996 Jan 27;312(7025):222.

10. Rawshani A, Rawshani A, Franzén S, Sattar N, Eliasson B, Svensson A-M, Zethelius B, Miftaraj M, McGuire DK, Rosengren A, et al. Risk Factors, Mortality, and Cardiovascular Outcomes in Patients with Type 2 Diabetes. N Engl J Med. 2018 16;379(7):633-44.

11. Jørgensen PG, Jensen MT, Mogelvang R, von Scholten BJ, Bech J, Fritz-Hansen T, Galatius S, BieringSørensen T, Andersen HU, Vilsbøll T, et al. Abnormal echocardiography in patients with type 2 diabetes and relation to symptoms and clinical characteristics. Diab Vasc Dis Res. 2016;13(5):32130 .

12. Jørgensen PG, Jensen MT, Biering-Sørensen T, Mogelvang R, Fritz-Hansen T, Vilsbøll T, Rossing P, Jensen JS. Burden of Uncontrolled Metabolic Risk Factors and Left Ventricular Structure and Function in Patients With Type 2 Diabetes Mellitus. J Am Heart Assoc Cardiovasc Cerebrovasc Dis. 2018 Sep 29;7(19):e008856.

13. Jørgensen PG, Jensen MT, Mogelvang R, Fritz-Hansen T, Galatius S, Biering-Sørensen T, Storgaard H, Vilsbøll T, Rossing P, Jensen JS. Impact of type 2 diabetes and duration of type 2 diabetes on cardiac structure and function. Int J Cardiol. 2016 Oct 15;221:114-21.

14. Jensen MT, Sogaard P, Andersen HU, Bech J, Hansen TF, Galatius S, Jørgensen PG, Biering-Sørensen T, Møgelvang R, Rossing P, et al. Prevalence of systolic and diastolic dysfunction in patients with type 1 diabetes without known heart disease: the Thousand \& 1 Study. Diabetologia. 2014 Apr;57(4):672-80.

15. Lindsay MM, Goodfield NE, Hogg KJ, Dunn FG. Optimising direct access ECHO referral in suspected heart failure. Scott Med J. 2000 Apr;45(2):43-4.

16. Boonman-de Winter LJM, Rutten FH, Cramer MJ, Landman MJ, Zuithoff NPA, Liem AH, Hoes AW. Efficiently screening heart failure in patients with type 2 diabetes. Eur J Heart Fail. 2015 Feb;17(2):187-95.

17. Ramírez J, Laguna P, Bayés de Luna A, Malik M, Pueyo E. QT/RR and T-peak-to-end/RR curvatures and slopes in chronic heart failure: Relation to sudden cardiac death. J Electrocardiol. 2014 Nov;47(6):842-8.

18. Ramírez J, Orini M, Mincholé A, Monasterio V, Cygankiewicz I, Bayés de Luna A, Martínez JP, Laguna P, Pueyo E. Sudden cardiac death and pump failure death prediction in chronic heart failure by combining ECG and clinical markers in an integrated risk model. Lionetti V, editor. PLOS ONE. 2017 Oct 11;12(10):e0186152.

19. Hawkins NM, Wang D, McMurray JJV, Pfeffer MA, Swedberg K, Granger CB, Yusuf S, Pocock SJ, Östergren J, Michelson EL, et al. Prevalence and prognostic implications of electrocardiographic left ventricular hypertrophy in heart failure: evidence from the CHARM programme. Heart. 2007 Jan;93(1):59-64. 
20. Hawkins NM, Wang D, McMurray JJV, Pfeffer MA, Swedberg K, Granger CB, Yusuf S, Pocock SJ, Östergren J, Michelson EL, et al. Prevalence and prognostic impact of bundle branch block in patients with heart failure: Evidence from the CHARM programme. Eur J Heart Fail. 2007;9(5):510-7.

21. Joseph J, Claggett BC, Anand IS, Fleg JL, Huynh T, Desai AS, Solomon SD, O'Meara E, Mckinlay S, Pitt B, et al. QRS Duration Is a Predictor of Adverse Outcomes in Heart Failure With Preserved Ejection Fraction. JACC Heart Fail. 2016;4(6):477-86.

22. Hummel SL, Skorcz S, Koelling TM. Prolonged Electrocardiogram QRS Duration Independently Predicts Long-Term Mortality in Patients Hospitalized for Heart Failure With Preserved Systolic Function. J Card Fail. 2009 Sep;15(7):553-60.

\section{Figures}




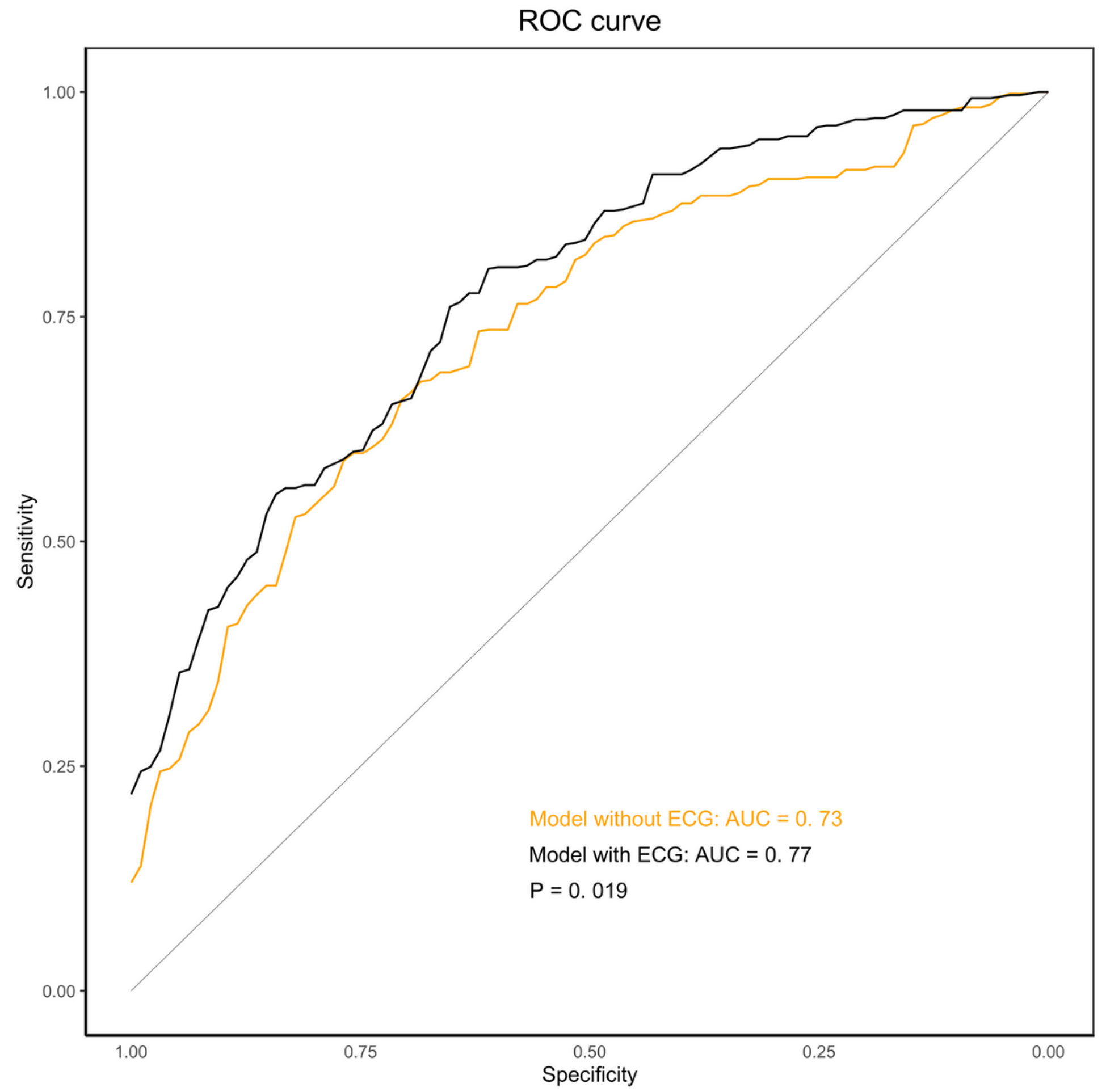

Figure 1

Receiver operating characteristic curve comparing abnormal to normal electrocardiogram in all included patients. Area under the curve (AUC). Electrocardiogram (ECG). 


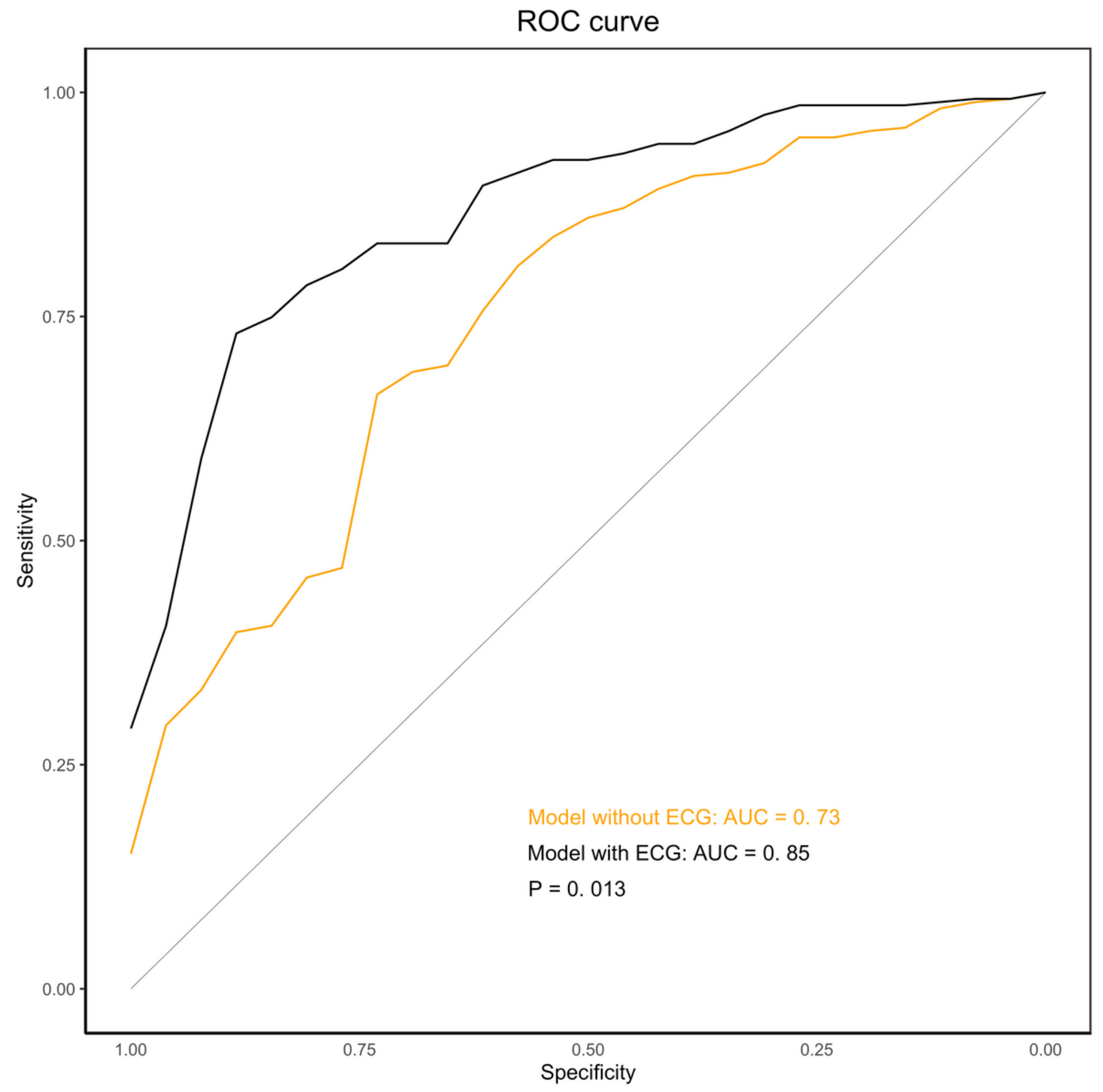

Figure 2

Receiver operating characteristic curve comparing abnormal to normal electrocardiogram in patients with 0-1 simple clinical risk factors. Area under the curve (AUC). Electrocardiogram (ECG). 

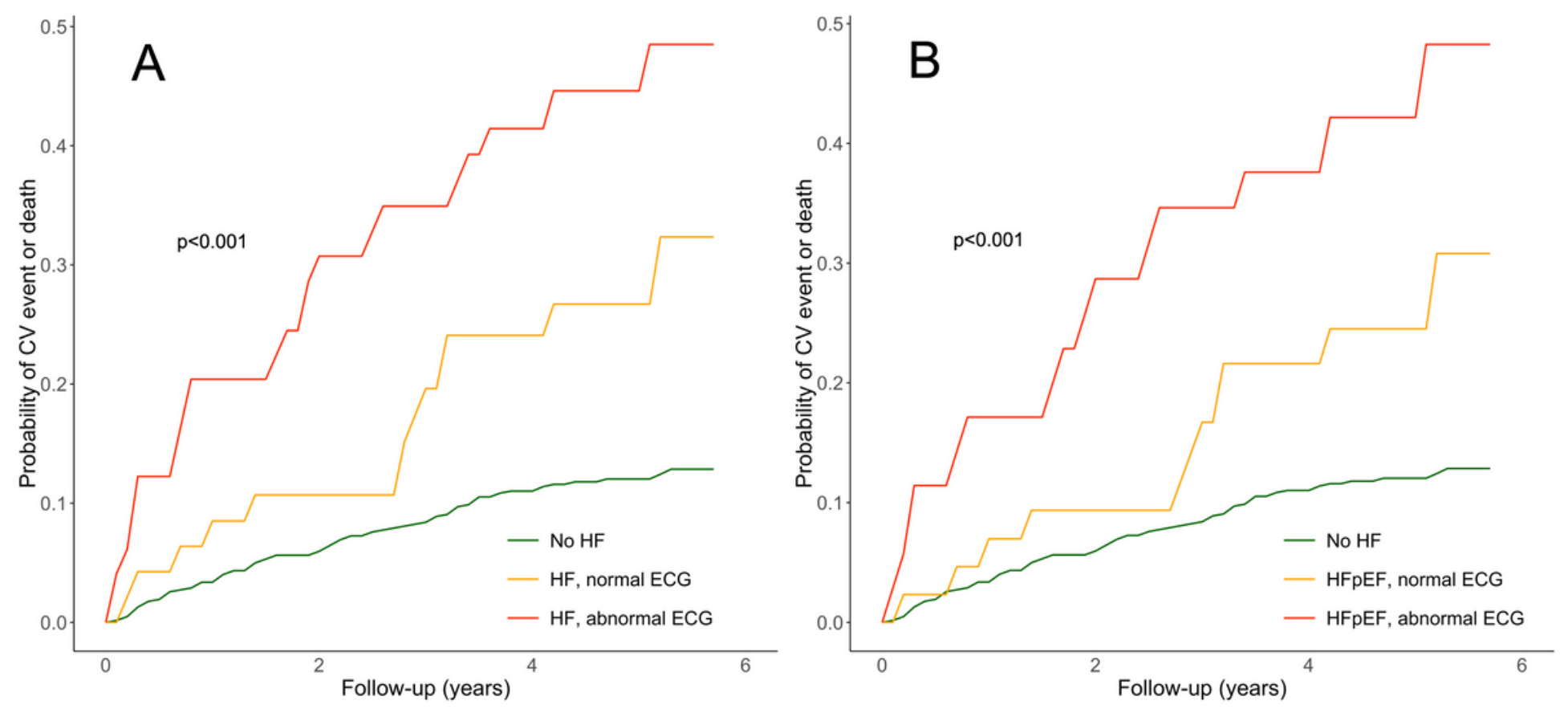

\section{Figure 3}

Cumulative incidence curves. A: all patients, B: excluding patients with heart failure with reduced ejection fraction. Cardiovascular (CV). Electrocardiogram (ECG). Heart failure (HF). Heart failure with preserved ejection fraction (HFpEF). 